Research Article

\title{
Study on Finite Element Model of the Prefabricated Reinforced Concrete Beam-Column Joints with Grouted Sleeves
}

\author{
Xiaoyong Luo $\mathbb{D}^{1,2}$ Hao Long $\mathbb{D}^{1,2}$ Ya Ou $\mathbb{D}^{3}$, and Shuang Dong $\mathbb{D}^{1}$ \\ ${ }^{1}$ School of Civil Engineering, Central South University, Changsha 41000, China \\ ${ }^{2}$ Hunan Prefabricated Construction Engineering Technology Research Centre, Changsha 41000, China \\ ${ }^{3}$ School of Civil Engineering, Central South University of Forestry and Technology, Changsha 41000, China \\ Correspondence should be addressed to Hao Long; longhao@csu.edu.cn
}

Received 25 January 2021; Revised 12 April 2021; Accepted 30 May 2021; Published 9 June 2021

Academic Editor: Weerachart Tangchirapat

Copyright ( $\odot 2021$ Xiaoyong Luo et al. This is an open access article distributed under the Creative Commons Attribution License, which permits unrestricted use, distribution, and reproduction in any medium, provided the original work is properly cited.

Based on the monotonic tensile test of grouted sleeve specimens conducted, this paper uses multifactor regression analysis to construct the equivalent constitutive relationship of grouted sleeve specimens under uniaxial tension. The study based on this constitutive relationship of grouted sleeves and the effect of bond and slip between steel and concrete were considered. The prefabricated reinforced concreted beam-column joints with grouted sleeves were presented with finite element software ABAQUS. The seismic behavior of prefabricated reinforced concreted beam-column joints with grouted sleeves under lowfrequency cyclic loading was then investigated. In addition, parametric studies via finite element analysis were performed to examine the influence of various parameters on the strength and energy dissipation capacity of the specimens. The simulation results show that plastic deformation was mainly observed near the beam-column interface; the hysteretic curve of this joint was plump. The test results showed that good energy dissipation and displacement ductility capacities can be achieved. The error of yield load between the numerical simulated and experimental result was $7.11 \%$, the error of peak load was $6.88 \%$, the error of ultimate load was $3.76 \%$, and the error of displacement ductility was $7.84 \%$. Results showed that the calculated results obtained in the paper agree well with test results from the references. The finite element model adopted in this paper can reflect the seismic behavior of the prefabricated reinforced concrete beam-column joints with grouted sleeves by using equivalent constitutive relation.

\section{Introduction}

Construction with the precast concrete (PC) method has gathered much attention as a substitution for convention cast-in-situ concrete structures because of its good quality, cost-effectiveness, accelerated construction speed, and lower energy consumption [1-4]. However, the relatively low reliability, high cost of the connections, and the low seismic performance of PC structures have limited their further application [3]. The seismic performance of the PC structure mainly depends on the connection type, the connection reliability between different precast members, and the arrangement of the precast members and cast-in-place concrete $[5,6]$. To date, many studies have been conducted on the connection between precast concrete members. The mainly used connections include traditional lap connections, improved lap connections, and grouted sleeve connection. Traditional lap connections, such as mechanical connections, welding connections, and lap connections, have been widely used in cast-in-situ concrete structures. However, even with longer lap lengths than other connection types, the seismic behavior of the traditional lap joints is still relatively low because of the short bond strength $[7,8]$. Besides, the complexity of connecting steel bars between precast components also hinders the wide application of precast concrete structures. In the last decades, more work has been done to solve the problems of the connections in the precast concrete frame by different researchers [9].

Among all the connections, the grouted sleeve has increased its popularity in the PC industry because of its 
simplicity and convenience for construction. The grouted sleeve effectively solves the technical problem of joint connection with precast concrete components [10]. The fully grouted sleeve and semigrouted sleeve are the two main types of grouted sleeves, while the semigrouted one is more commonly used in practice [11]. The semigrouted sleeve has two ends: one end with threads and the threaded steel bar from the precast part installed in it, and the other end is plain with a deformed steel bar from the postcast part in the sleeve. After the two parts are placed in the sleeve, high-strength grout will be filled in the sleeve and the precast and postcast parts are connected.

The seismic behavior of the precast concrete frame is significantly different from the traditional cast-in-situ reinforced concrete because the precast and postcast concrete parts are connected by the grouted sleeves instead of steel reinforcement. Extensive experimental and numerical work has been done to study the seismic behavior of the grouted sleeve connections. There are two widely used methods to simulate the grouted sleeves in the structure: the first one uses the solid element to model all the connecting components [12-14], which is accurate but with significantly high computational efforts and the other method assumes the sleeve connection is always reliable and models the sleeve as steel reinforcement [15]; this method is computationally efficient and easy to operate, but it fails to capture the actual force in the sleeve and the influence of the sleeve joint on the whole structure. Thus, the simulation results are usually not accurate enough. Besides, in the current simulations, the effects of the interface at the fresh concrete and existing concrete is usually ignored, which may also reduce the simulation accuracy.

In this paper, the tensile constitutive relationship of the grouted sleeve connection is firstly constructed using multifactor linear statistical analysis on the pull-out test results. Then, this relation is applied to the finite element model of a prefabricated beam-column joint with grouted sleeves, and the influences of the fresh and hardened concrete interface on the joint are also considered. It shows that the simulation fits the experiment results well, so the refined finite element model based on the equivalent grouted sleeve constitutive relation can accurately capture the seismic performance of the beam-to-column joint.

\section{Uniaxial Tensile Test and Equivalent Constitutive Relation of Grouted Sleeve Reinforcement}

2.1. Uniaxial Tensile Test Result and Analysis. The strainstress relationship of the grouted sleeve is firstly received based on the pull-out test results by Liu et al. [16]. 26 pull-out tests have been done to get the tensile constitutive relationship of the grouted sleeves. The sleeves were made by either cast iron or steel and the pull-out tests were carried out by a $100 \mathrm{kN}$ universal testing machine with a constant loading rate at $1 \mathrm{kN} / \mathrm{s}$; a few typical stress-strain curves of the grouted sleeves were selected as shown in Figure 1. It can be found that the tensile behavior of the grouted sleeve joint

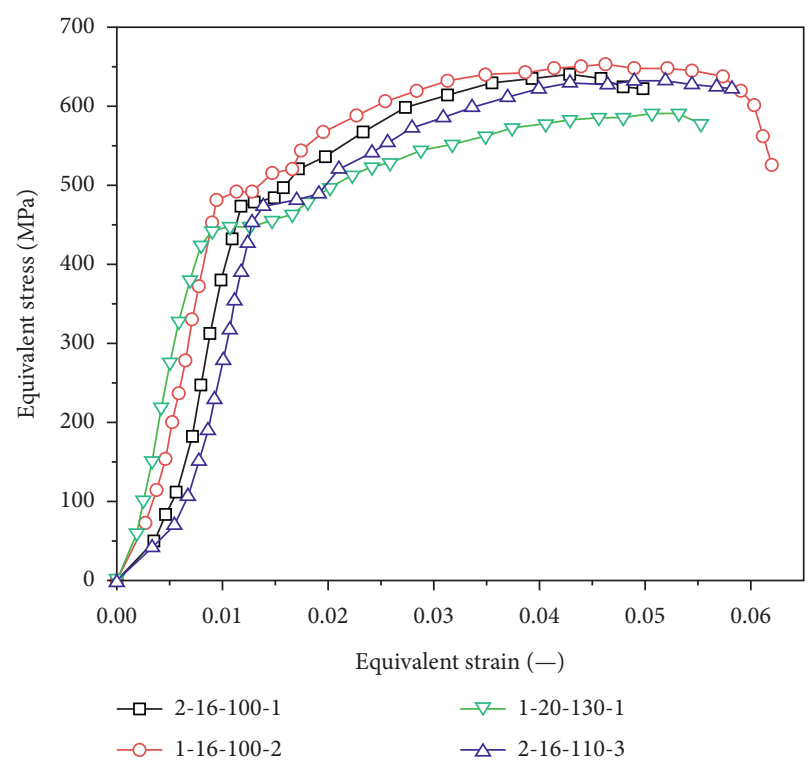

FIgURE 1: The stress-strain curves of the grouted sleeve.

specimens was similar to steel, with firstly a linear increase stage, followed by a yield plateau, and then reached the ultimate strength and failure. The details of the grouted sleeve joints in the test are listed in Table 1. According to the observations of the test results, the parameters that may affect the constitutive relation of grouted sleeve joints include the diameter of reinforcement $d$, length of sleeve $L_{1}$, length of grouted segment $L_{2}$, the external diameter of the sleeve $D_{1}$, the inner diameter of the sleeve $D_{2}$, the yield strength of reinforcement, and ultimate strength of reinforcement; details of grouted sleeve are shown in Figure 2. Based on the experimental results, an equivalent constitutive relation of grouted sleeve joint similar to reinforcement is proposed.

\subsection{The Equivalent Constitutive Relation of Reinforcement} Joint with Grouted Sleeve. As discussed in Section 2.1, the grouted sleeve joint specimens have similar characteristics as the reinforcement; therefore, a trilinear constitutive model is selected to simulate the reinforcement joint with grouted sleeve under uniaxial tension, as shown in Figure 3. In Figure 3, point $\mathrm{A}$ and Point $\mathrm{C}$ are the equivalent yield point and ultimate load point of the grouted sleeve, respectively; segment $A B$ is the yield plateau of the grouted sleeve.

2.3. The Value of Characteristic Point Parameter. The characteristic points $\mathrm{A} \sim \mathrm{C}$ in the trilinear constitutive model for the grouted sleeve joint were decided based on the statistical analysis on the strain-stress data using a statistical software SPSS; the results are as listed in Tables 2 and 3. The parameters considered in the analysis include anchorage length, yield strain, the diameter of reinforcement, the total length of sleeve, the outer diameter of the sleeve, the inner diameter of the sleeve, and the diameter of reinforcement. Value $t$ in Tables 2 and 3 represents the test statistic regression coefficient, sig. is the associated probability value, 
TABLE 1: The performance parameter processing results of the grouted sleeve.

\begin{tabular}{|c|c|c|c|c|c|c|c|}
\hline $\begin{array}{l}\text { Joint } \\
\text { number* }\end{array}$ & $\begin{array}{l}\text { Yield strength } \\
(\mathrm{MPa})\end{array}$ & $\begin{array}{l}\text { Ultimate strength } \\
(\mathrm{MPa})\end{array}$ & $\begin{array}{l}\text { Steel bar diameter } \\
(\mathrm{mm})\end{array}$ & $L_{1} / L_{2}$ & $D_{1} / D_{2}$ & $\begin{array}{l}\text { Equivalent yield } \\
\text { strain }\end{array}$ & $\begin{array}{l}\text { Equivalent ultimate } \\
\text { strain }\end{array}$ \\
\hline 1-16-100-1 & 465.94 & 643.42 & 16 & \multirow{11}{*}{$\begin{array}{c}159 / \\
110\end{array}$} & \multirow{9}{*}{$40 / 33$} & 0.0089 & 0.058 \\
\hline $1-16-100-2$ & 465.51 & 624.95 & 16 & & & 0.0081 & 0.052 \\
\hline $1-16-100-3$ & 468.2 & 625.37 & 16 & & & 0.0083 & 0.054 \\
\hline $1-16-110-1$ & 496.75 & 625.11 & 16 & & & 0.0079 & 0.0563 \\
\hline $1-16-110-2$ & 440.82 & 602.00 & 16 & & & 0.0074 & 0.0522 \\
\hline $1-16-110-3$ & 465.51 & 630.77 & 16 & & & 0.0069 & 0.0521 \\
\hline 1-16-110-s1 & 463.78 & 625.64 & 16 & & & 0.0085 & 0.0568 \\
\hline $1-16-110-s 2$ & 465.83 & 624.84 & 16 & & & 0.0089 & 0.0587 \\
\hline $1-16-110-\mathrm{s} 3$ & 469.28 & 629.95 & 16 & & & 0.0077 & 0.0542 \\
\hline $1-20-130-1$ & 429.52 & 584.02 & 20 & & \multirow{6}{*}{$45 / 38$} & 0.0073 & 0.0552 \\
\hline $1-20-130-2$ & 426.94 & 584.55 & 20 & & & 0.0069 & 0.051 \\
\hline $1-20-130-3$ & 441.97 & 604.82 & 20 & $195 /$ & & 0.0086 & 0.0588 \\
\hline $1-20-143-1$ & 451.91 & 604.00 & 20 & 143 & & 0.0084 & 0.0522 \\
\hline $1-20-143-2$ & 450.15 & 610.86 & 20 & & & 0.0078 & 0.06 \\
\hline $1-20-143-3$ & 472.81 & 637.65 & 20 & & & 0.0072 & 0.052 \\
\hline $2-16-100-1$ & 468.07 & 627.92 & 16 & \multirow{9}{*}{$\begin{array}{c}150 / \\
110\end{array}$} & \multirow{9}{*}{$40 / 32$} & 0.0077 & 0.058 \\
\hline $2-16-100-2$ & 472.65 & 630.99 & 16 & & & 0.0082 & 0.0568 \\
\hline $2-16-100-3$ & 472.65 & 630.89 & 16 & & & 0.0081 & 0.052 \\
\hline $2-16-110-1$ & 470.98 & 628.51 & 16 & & & 0.008 & 0.0517 \\
\hline $2-16-110-2$ & 462.41 & 626.23 & 16 & & & 0.0077 & 0.0527 \\
\hline $2-16-110-3$ & 461.98 & 627.17 & 16 & & & 0.0074 & 0.0577 \\
\hline 2-16-110-s1 & 463.68 & 626.29 & 16 & & & 0.0075 & 0.0574 \\
\hline $2-16-110-s 2$ & 458.5 & 623.49 & 16 & & & 0.0069 & 0.0572 \\
\hline $2-16-110-\mathrm{s} 3$ & 463.41 & 625.92 & 16 & & & 0.0079 & 0.055 \\
\hline $2-20-130-1$ & 440.26 & 586.86 & 20 & $190 /$ & \multirow{2}{*}{$44 / 36$} & 0.0081 & 0.0584 \\
\hline $2-20-143-1$ & 443.81 & 596.17 & 20 & 143 & & 0.0084 & 0.0538 \\
\hline
\end{tabular}

"In the joint number: the first number "1" represents steel and "2" represents cast iron, the second number represents the diameter of the steel, the third number represents the anchorage length, and the last number " $1 \sim 3$ " represents the three repetitive specimens; if there is an " $s$ " before the last number, it represents the steel is placed eccentrically in the sleeve. For example, "1-16-100-1" represents the first steel sleeve specimen with a diameter of $16 \mathrm{~mm}$ and an anchorage length of $100 \mathrm{~mm}$.

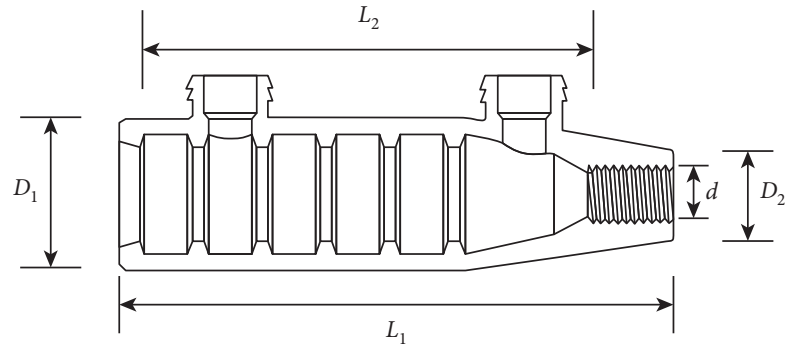

(a)

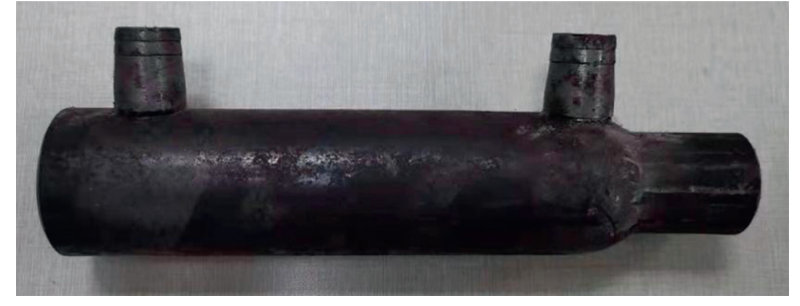

(b)

Figure 2: Simplified diagram of the grouted sleeve. (a) Details of the grouted sleeve. (b) A grouted sleeve sample.

the significance of the stress at the characteristic point is the yield strength of the reinforcement $f_{y}$, and the stress at the characteristic point is an increasing function of the yield strength of reinforcement. The yield strength of reinforcement was selected as an independent variable for multiple regression; the results are shown in Table 4 . The goodnessof-fitting square $\left(R^{2}\right)$ is 0.668 , the statistic $F=19.338$, the associated probability value sig. $=0.00$, the regression is relatively significant, and the fitting result is obtained as shown in

$$
\sigma_{A}=\sigma_{B}=-0.813 f_{y}+834.52
$$

Table 5 shows the fitting results of strain at each characteristic point; similarly, the results of other characteristic points can be obtained as shown in the following equations:

$$
\begin{aligned}
& \sigma_{C}=0.367 f_{y}+396, \\
& \varepsilon_{A}=-0.369 \times \varepsilon_{y}+6.983 E^{-8} \times L_{2}+0.006, \\
& \varepsilon_{B}=-0.79 \times \varepsilon_{y}+1.073 E^{-5} \times L_{2}+0.04, \\
& \varepsilon_{C}=0.0369 \times \varepsilon_{y}+0.38 E^{-6} \times L_{2}+0.067 .
\end{aligned}
$$




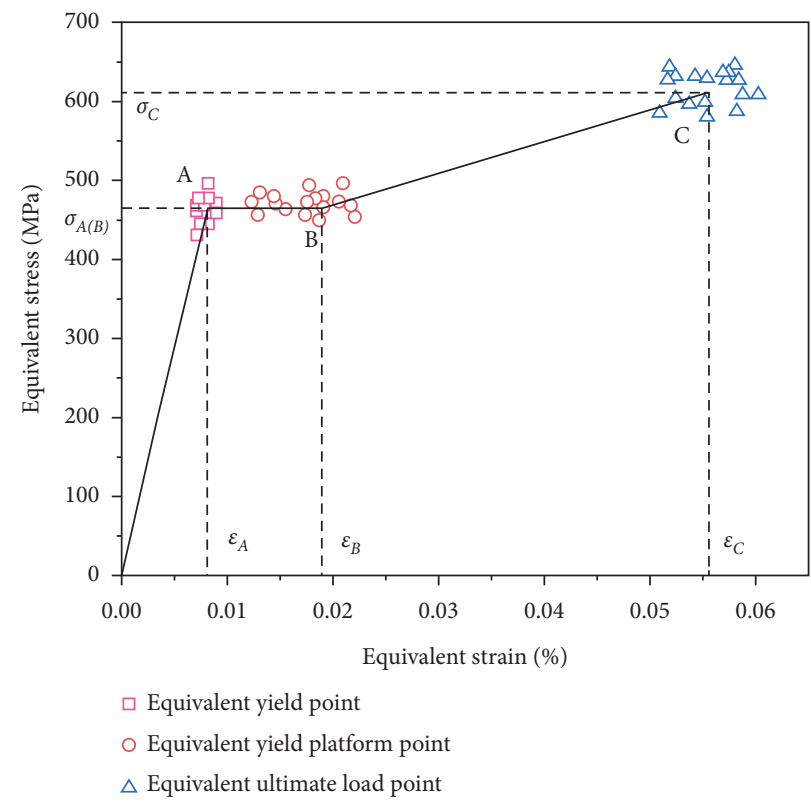

Figure 3: The trilinear constitutive model of the grouted sleeve.

TABLE 2: The characteristic points significance analysis of stress.

\begin{tabular}{lcccc}
\hline Characteristic point & Selected variable & Steel bar diameter & Total length of sleeve & Yield strength of reinforcement \\
\hline \multirow{2}{*}{ Yield strength point A } & Significance sig. & 0.288 & 0.901 & 0.00 \\
& Value $t$ & -1.089 & 0.901 & -4.398 \\
Yield strength point C & Significance sig. & 0.263 & 0.892 & 0.00 \\
& Value $t$ & -2.341 & 0.521 & -5.339 \\
\hline
\end{tabular}

TABLE 3: The characteristic points significance analysis of strain.

\begin{tabular}{lccccc}
\hline Characteristic point & Selected variable & Steel bar diameter & Total length of sleeve & Yield strength of reinforcement & Selected variable \\
\hline \multirow{2}{*}{ Yield strength point A } & Significance sig. & 0.076 & 0.00 & 0.288 & 0.901 \\
& Value $t$ & 15.23 & 29.23 & -1.089 & -3.811 \\
Yield platform B & Significance sig. & 0.064 & 0.00 & 0.345 & 0.832 \\
& Value $t$ & 10.73 & 26.78 & -3.066 & -4.312 \\
\multirow{2}{*}{ Yield strength point C } & Significance sig. & 0.014 & 0.00 & 0.345 & 0.832 \\
& Value $t$ & 16.23 & 19.55 & -4.098 & -5.152 \\
\hline
\end{tabular}

TABLE 4: The stress fitting results of the characteristic points.

\begin{tabular}{lccccc}
\hline Characteristic point & Value $F$ & $R$ square & Yield strength of reinforcement & Significance & Constant \\
\hline Yield strength point A & 19.338 & 0.668 & -0.813 & 0.000 \\
Ultimate strength C & 28.114 & 0.589 & 0.367 & 0.000 & 396.52 \\
\hline
\end{tabular}

TABle 5: The strain fitting results of the characteristic points.

\begin{tabular}{lcccc}
\hline Characteristic point & Value $F$ & $R$ square & Steel yield strain & Anchorage length of reinforcement \\
\hline Yield strain point A & 119.231 & 0.687 & -0.369 & $6.98 E-8$ \\
Yield strain point B & 30.887 & 0.778 & -0.790 & $1.073 E-5$ \\
Yield strain point C & 78.329 & 0.748 & 0.0396 & $0.380 E-6$ \\
\hline
\end{tabular}




\section{Finite Element Model Verification of a Prefabricated Beam-Column Joint with Grouted Sleeves}

3.1. Details of the Test. A fine finite element model based on the grouted sleeve joint pull-out tests was established to simulate the low-frequency cyclic test on a beam-to-column connection, as shown in Figures 4 and 5. In the tests, the precast beam and column ends were jointed by the grouted sleeve and then connected as a whole using postcast concrete. The size and reinforcement details of the specimen are shown in Figure 4. The designed axial load ratio was 0.3 , the designed strength grade of precast concrete member was C30 (compressive strength $=30 \mathrm{MPa}$ ), the designed strength grade of postcast concrete was C40 (compressive strength $=40 \mathrm{MPa}$ ), the longitudinal reinforcements of the beam and column were HRB335, and the stirrups were HPB300. The mechanical parameters of the materials in the specimen are listed in Table 6 . To ensure the bonding and anchoring strength of the steel reinforcement, the diameter of the sleeve was $40 \mathrm{~mm}$, the length of the sleeve was $159 \mathrm{~mm}$, the length of the grouted segment was $110 \mathrm{~mm}$, the concrete cover thickness of the grouted sleeves was $20 \mathrm{~mm}$, and the concrete cover thickness of the steel reinforcement was $34 \mathrm{~mm}$. The loading condition of this test [17] was as shown in Figure 5, the bottom of the specimen was fixed by a directional hinge, and the horizontal movement of the specimen top was constrained by a rod. Vertical loads were applied by the servo machine at the column ends. Force control was firstly used, following the scheme as shown in Figure 5 until the specimen yield [18] (when the inflection point first emerged in skeleton curve); then, displacement control was adapted, with the yield displacement as the grade-distinction, cyclic loading each grade-distinction twice. The test ended when the load decreased to be below $85 \%$ of the peak load. In Figure 5, $P_{y}$ is the yield load, $\Delta$ is the loading displacement at the column ends, and $\Delta_{y}$ is the yield displacement. The failure mode, deformation capacity, energy dissipation capacity, ductility, and other parameters of beam-to-column joints of postcast concrete with the grouted sleeve were analyzed.

\subsection{Fine Finite Element Modeling}

3.2.1. Material Constitutive Model. The concrete damage plastic model in ABAQUS was used for the concrete; and the reinforcement behavior was modeled as bilinear, with the slope of the elastic stage taken as the elastic modulus of steel and the slop of the plastic stage as 0.01 , the yield strength and ultimate strength were obtained by the material test. The grouted sleeve constitutive model adopts the equivalent constitutive model proposed in equations (1) (5).

3.2.2. Bond-Slip of Reinforced Concrete. Spring A was used to simulate the bond and slip between the concrete and the longitudinal reinforcement, and the axial spring stiffness was determined by the Eligehausen model [19]. The spring element in the radial direction of reinforcement mainly simulates the dowel action and the vertical displacement of the reinforcement nodes and the concrete nodes inside the stirrup, which has a low influence on the bond-slip between the concrete and longitudinal reinforcement. The maximum elastic modulus of steel and concrete was used as the spring stiffness along the radial direction of the reinforcement; in this paper, the space between the springs along the longitudinal reinforcement was set to be $50 \mathrm{~mm}$.

\subsubsection{Simulation of Precast and Postcast Concrete Interface.} Liu and Zhao [20] and Zhang [21] found that the ultimate tensile strength of the concrete with precast and postcast interface was only $80 \%$ of the tensile strength of normal concrete cast once as a whole, and the load dropped rapidly after reaching the ultimate load. An ideal elastic-plastic model was assumed as the compressive behavior at the concrete to reinforcement interface, and the ultimate compressive strength is the compressive strength of concrete. Thus, the normal force-displacement relationship of the joint spring is shown in Figure 6.

A large number of experimental studies have been conducted on the interface shear strength of unconfined precast and postcast concrete; the shear strength at the interface is mainly composed of three parts: internal cohesive force in the concrete, friction force, and shear resistance of reinforcement. Fan [22] established the formula for the interfacial shear strength at the precast and postcast concrete interface after comprehensively considering several factors affecting the shear strength of the interface, as shown in equation (6), and then determined the calculation parameters by regression analysis. The tangential force-displacement relationship of the spring elements can be obtained by substituting the relevant parameters from the test to the equation:

$$
\tau_{u}=0.114 \Delta \cdot f_{t d}+\frac{1}{L} 2.464 \times \Delta E_{s} \mu_{s} \lambda_{\mathrm{con}} f_{t d}+0.013 \mu_{s} \lambda_{\mathrm{coi}}^{2} .
$$

3.2.4. Element Selection. In this paper, eight-node hexahedral (brick) elements (C3D8R) were used for concrete, twonode linear truss elements (T3D2) were used to model reinforcements [23], the grouted sleeve joints were simulated by nonlinear Spring A, and the tangential and normal connection at the precasting and postcasting concrete interface were simulated by nonlinear spring elements. The fine finite element model is shown in Figure 7. The nonlinear relationship of the springs is reflected by the respective force-displacement (F-D) curves. The F-D curve is calculated by the normal constitutive and tangential constitutive of the precasting and postcasting concrete interface.

\subsection{Simulation Verification of Grouted Sleeve Joint}

3.3.1. Failure Modes and Cracking Development. Specimen was loaded under low-frequency cyclic loading. At the initial stage of loading, the force in the core area of the 


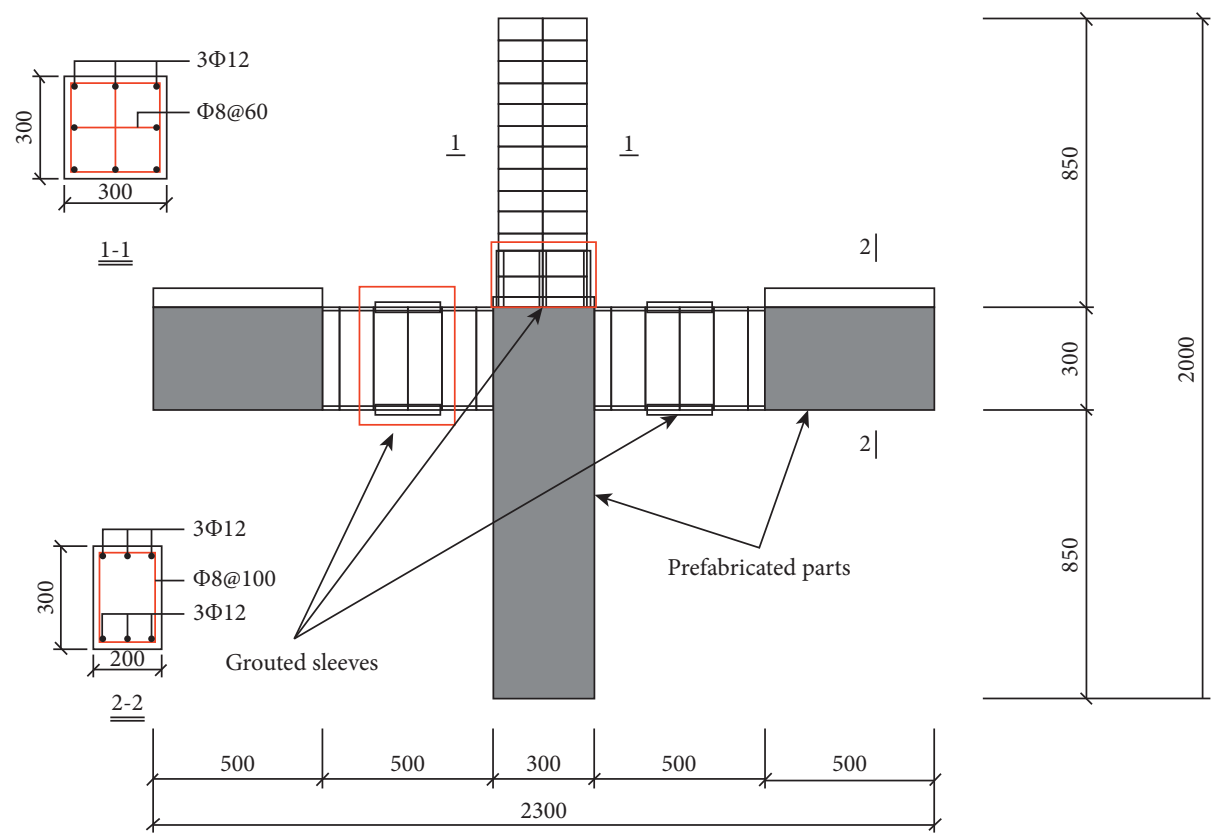

FIgURE 4: The physical dimension and reinforcement of test pieces (unit: $\mathrm{mm}$ ).

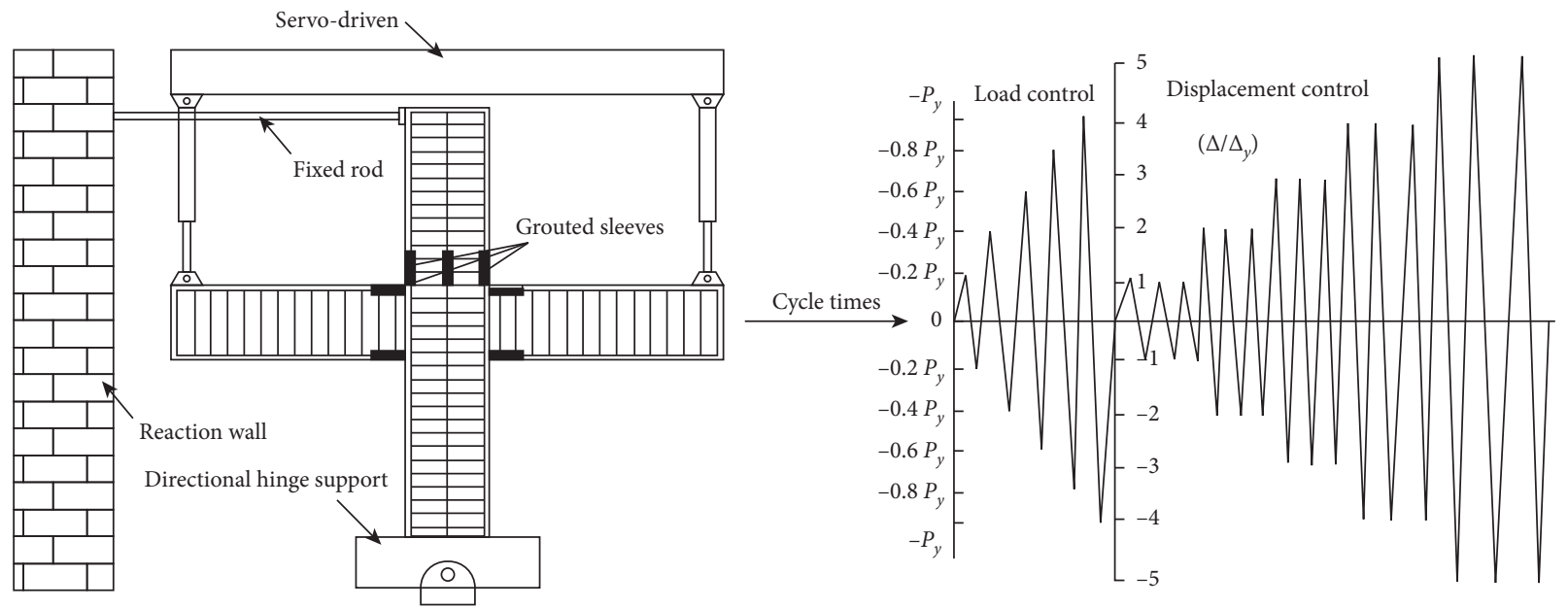

FIGURE 5: The loading device of test pieces.

TABLE 6: The mechanical properties.

\begin{tabular}{lcc}
\hline Parameter type & Performance parameter & Numerical value \\
\hline & $\begin{array}{c}\text { Cube compressive strength } \\
\text { Concrete }\end{array}$ & 41.2 \\
& Axial compressive strength & 30.63 \\
& $\quad$ (MPa) & $3.26 e 4$ \\
Stressed steel & Elastic modulus (MPa) & $2 e 5$ \\
bar & Elastic modulus (MPa) & 371 \\
& Yield strength (MPa) & 531 \\
\hline
\end{tabular}

beam-column joint conforms to the Strut-and-Tie model as shown in Figure 8(a). Concrete crushing firstly occurs at the beam end near the core area, as shown in Figure 8(b). When the load reaches the crack load, due to the uneven distribution of beam ends stiffness, vertical cracks appear at the interface between the end of the grouted sleeve and the beam-to-column joint. After the concrete at the beam end crashed, the force in the beam decreases sharply, and the force in the structure is mainly taken by the steel frame and concrete column; the stress in the core area of the beamcolumn joint no longer follows the Strut-and-Tie model. As the loading increases, the cracking gradually expands to the middle part of the beam. When the load reaches $30 \mathrm{kN}$, the crack developed through the beam height, and inclined cracks appear in the core area. By the end of the tests, the cracks are mainly distributed at the beam-column interface, the two ends of the grouted sleeve, and the region within $500 \mathrm{~mm}$ from the column end. After the concrete at the beam end yield, the stress at the core stirrups increases sharply and reaches the yield stress, as shown in Figure 8(d). 


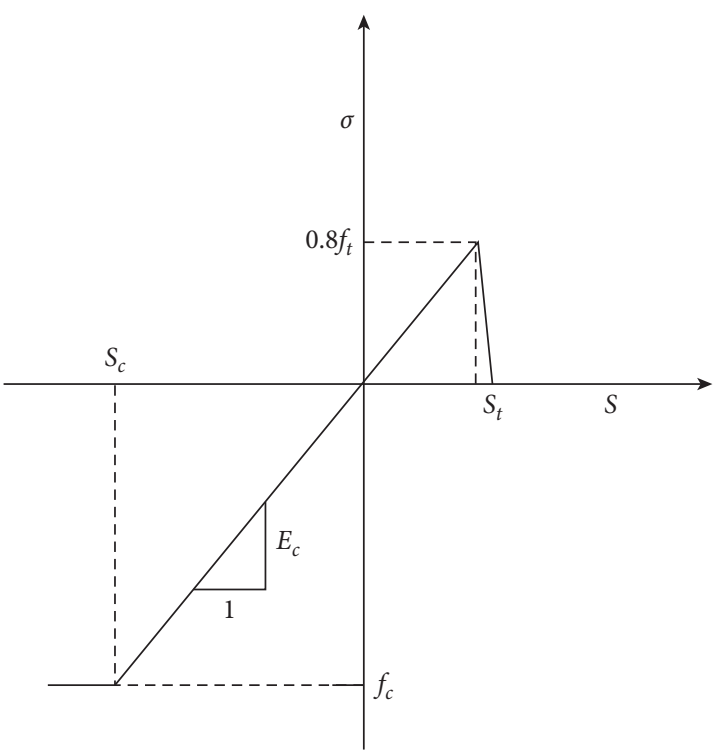

FIGURE 6: The normal force displacement of nonlinear spring.

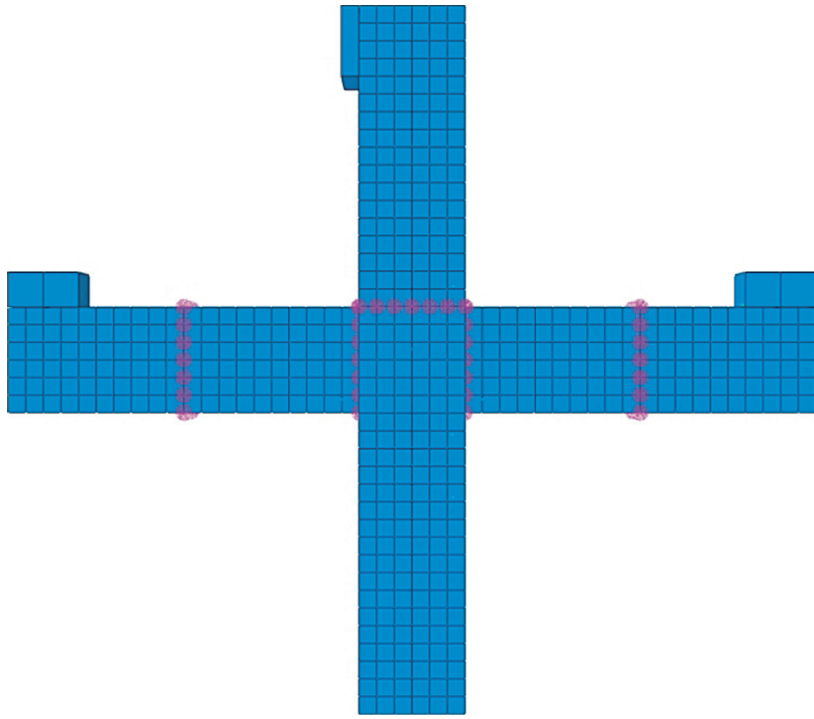

(a)

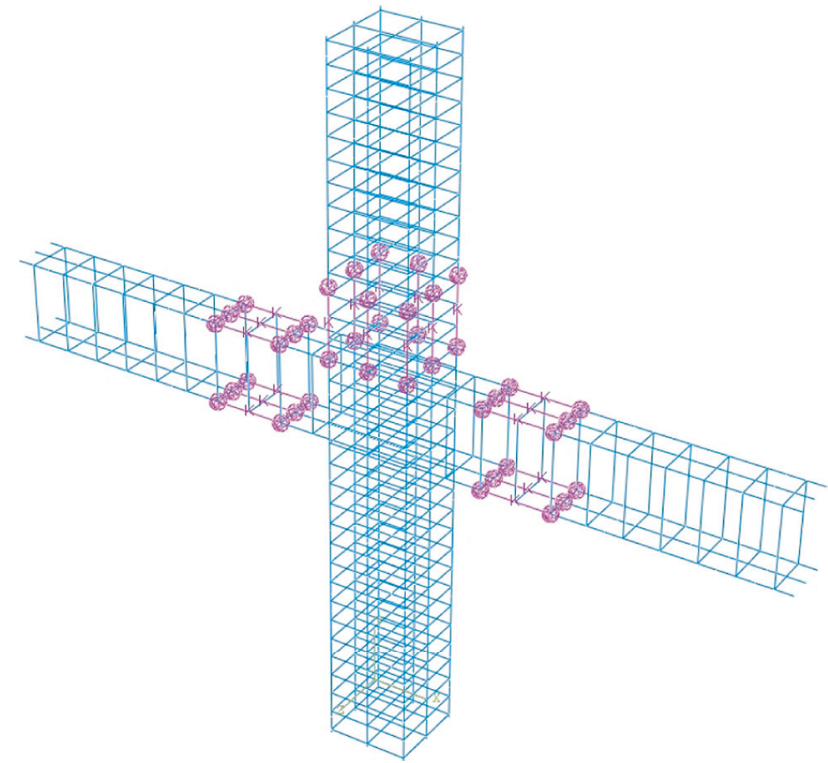

(b)

Figure 7: Finite element model of concrete interface and grouted sleeve. (a) Simulation of postcast concrete interface. (b) Simulation of sleeve grouted joints.

When loading at the peak displacement, most of the core stirrups are yield, and the stress in the beam is relatively small; the structure enters the failure stage, and crushing failure happens in the concrete at the beam ends. The finite element simulation successfully captures the cracking development in the structure, and the failure modes in the model are identical to those in the test, shown in Figure 9.

3.3.2. Bearing Capacity and Ductility. The skeleton curves of the finite element simulation and the tested beam-to-column joints of the prefabricated concrete structure with grouted sleeve joints are as shown in Figure 10. The numerical simulation result of the ascending segment of the skeleton curve fits well with the experimental result, and the initial stiffness and peak load of the numerical simulation are close to the test results. However, as the plastic damage of the grouted sleeve is not considered in the model at the descending segment of the skeleton curve, the loading capacity from the numerical simulation is smaller than the test results. The yield load, yield displacement, peak load, peak displacement, ultimate load, and ultimate displacement from the numerical model are shown in Table 7 . In Table 7, the displacement ductility coefficient of the specimen [24] is 


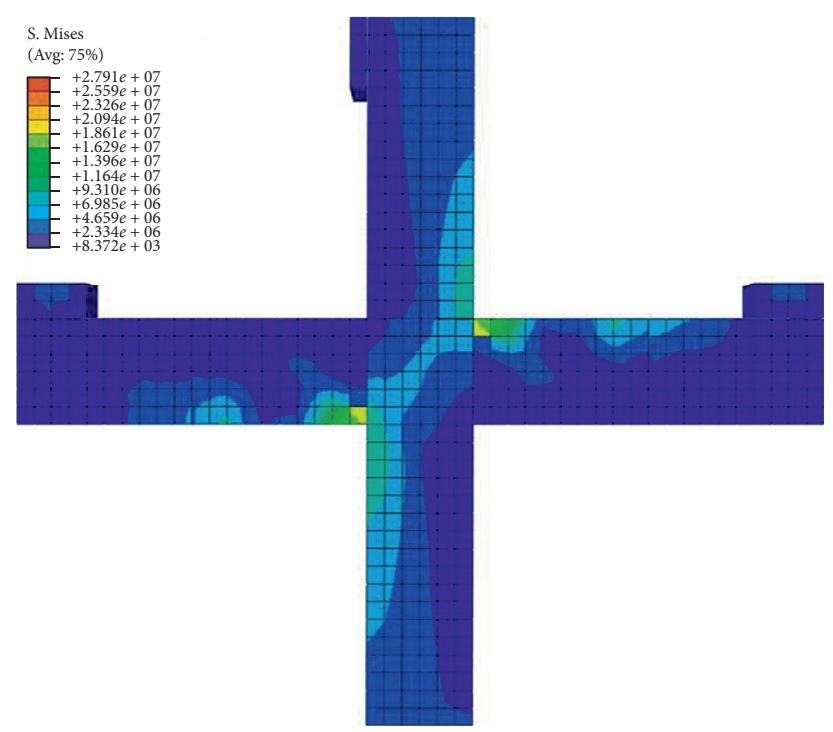

(a)

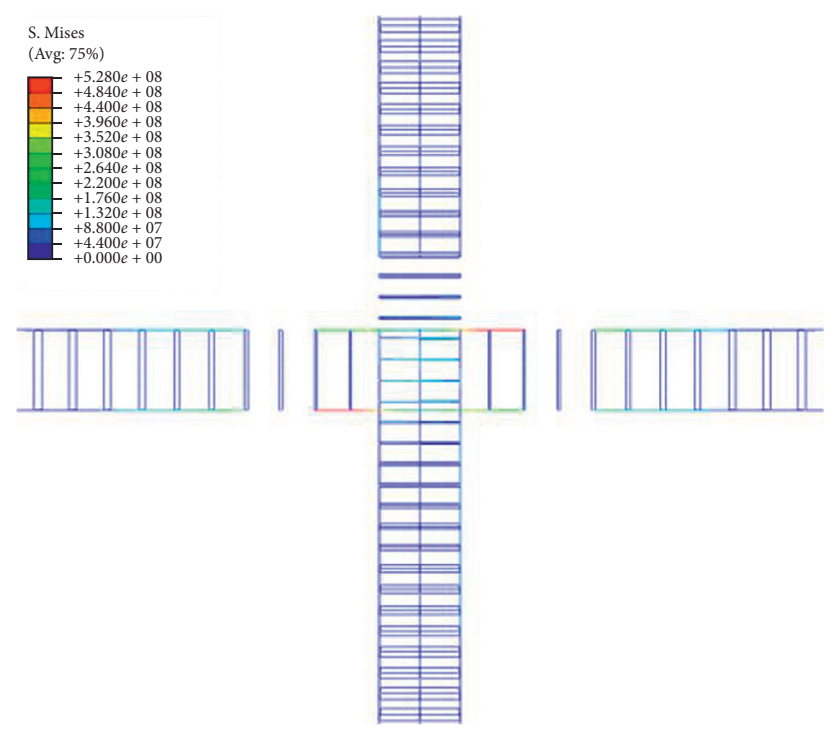

(c)

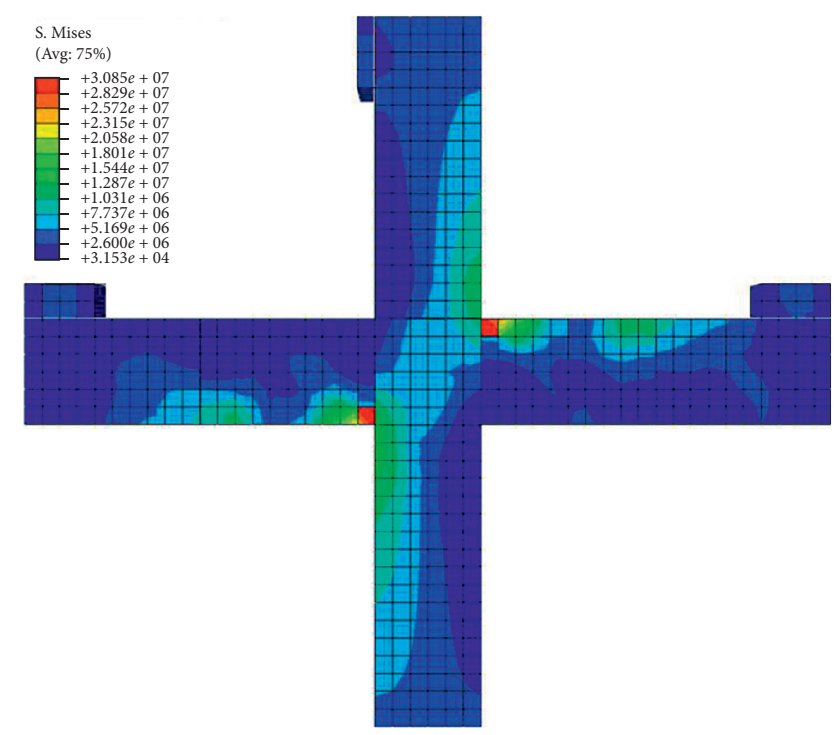

(b)

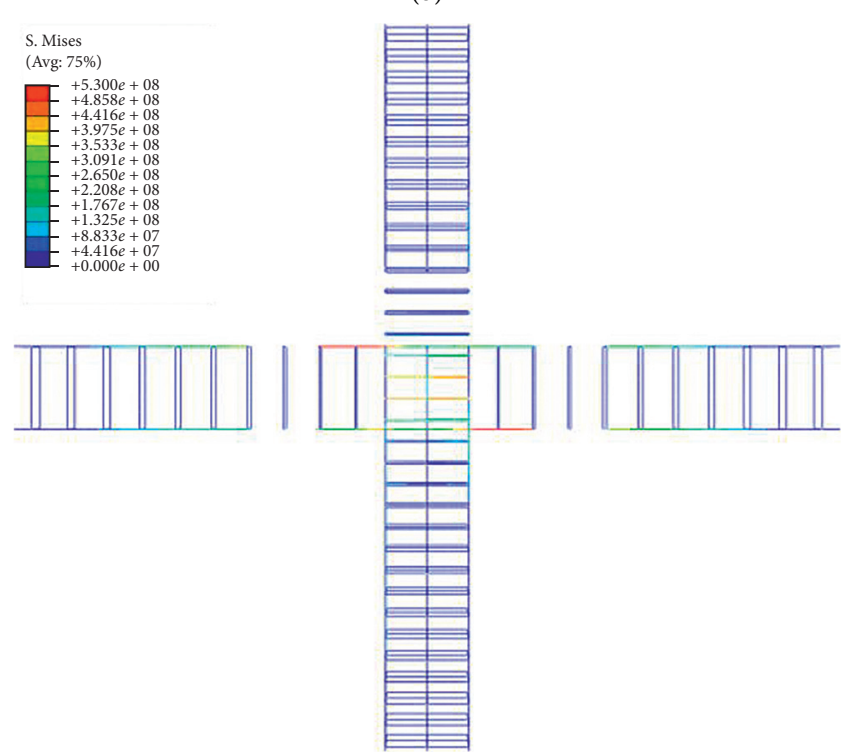

(d)

Figure 8: Mises stress nephogram of the finite element simulation. (a) The stress form of the Strut-and-Tie rod in the core area of the beamcolumn joint. (b) Concrete at beam ends is crushed. (c) Beam stress reinforcement begins to yield. (d) The core stirrups begin to yield.

calculated as the ratio of the ultimate displacement to the yield displacement, that is, $\mu=\left(\Delta_{u} / \Delta_{y}\right)$. The difference between the finite element simulation result and the test result of the specimen is within $8 \%$; the bearing capacity of the structure can be effectively simulated; the simulation errors of yield load, peak load, and ultimate load are $7.11 \%$, $3.76 \%$, and $4.72 \%$, respectively, and the error of displacement ductility coefficient is $7.84 \%$. So, the simulation can capture the experiments' results quite well.

3.3.3. Load-Displacement Hysteretic Curve. The hysteresis curves of the finite element model and the tests on the postcast concrete beam-to-column joints with grouted sleeve joints are shown in Figure 11, and the results are shown in Table 8. Comparison of the analytical and experimental results showed that the hysteresis curves obtained from ABAQUS analyses were quite similar. The shape of the hysteresis curves is relatively plump, which shows that the prefabricated beam-column joints with grouted sleeve joints have a high energy consumption capacity.

Due to the fact that the spring element and steel truss element of the simulated sleeve cannot define the constitutive relation under cyclic load in ABAQUS, when applying forward load, the finite element simulation results are $3.76 \%$ lower than the test results, the area enclosed by the hysteresis curve is relatively small when the load is reversed, and the load capacity from the finite element simulation is $13.23 \%$ lower than the test. At the late loading stage, the finite element model takes the bond-slip effect into account, the 


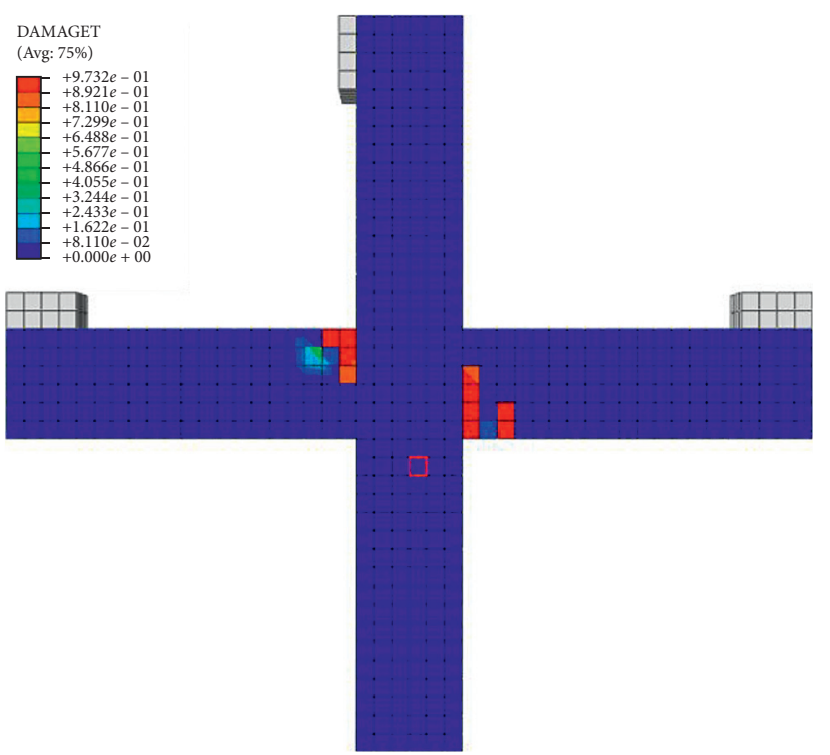

(a)

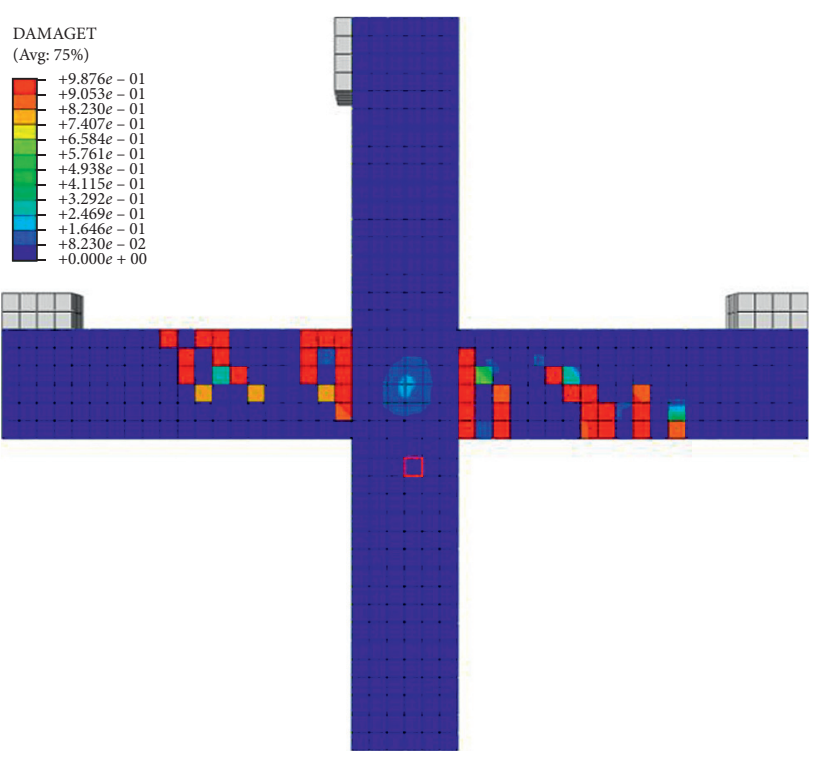

(c)

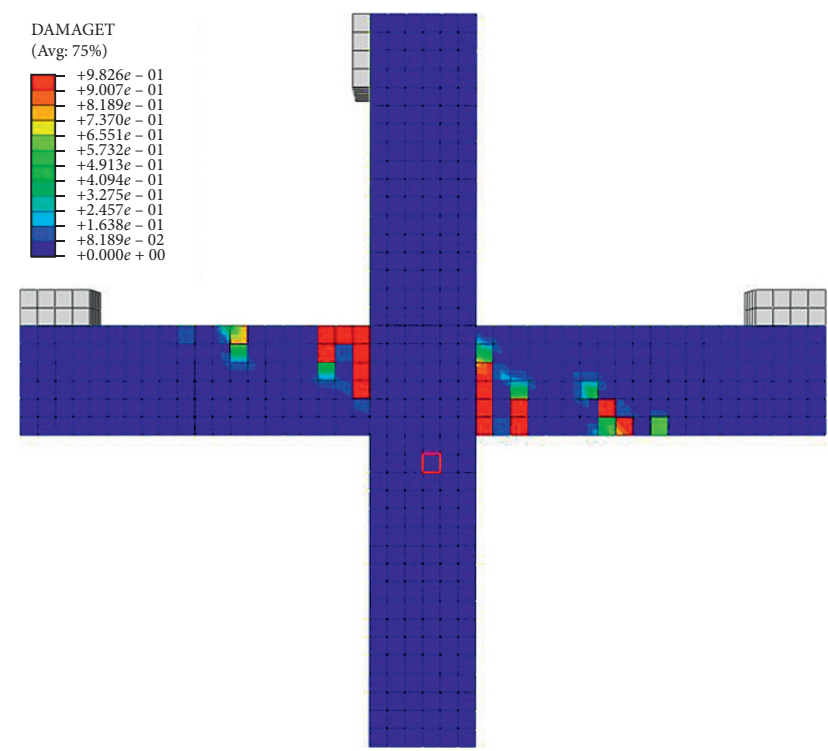

(b)

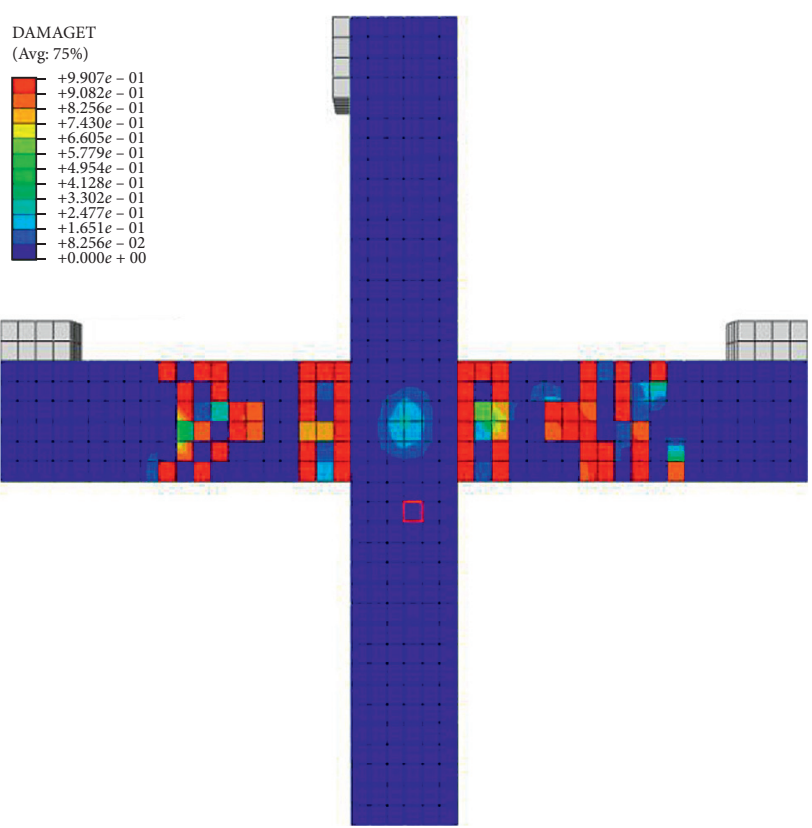

(d)

FIGURE 9: Continued. 


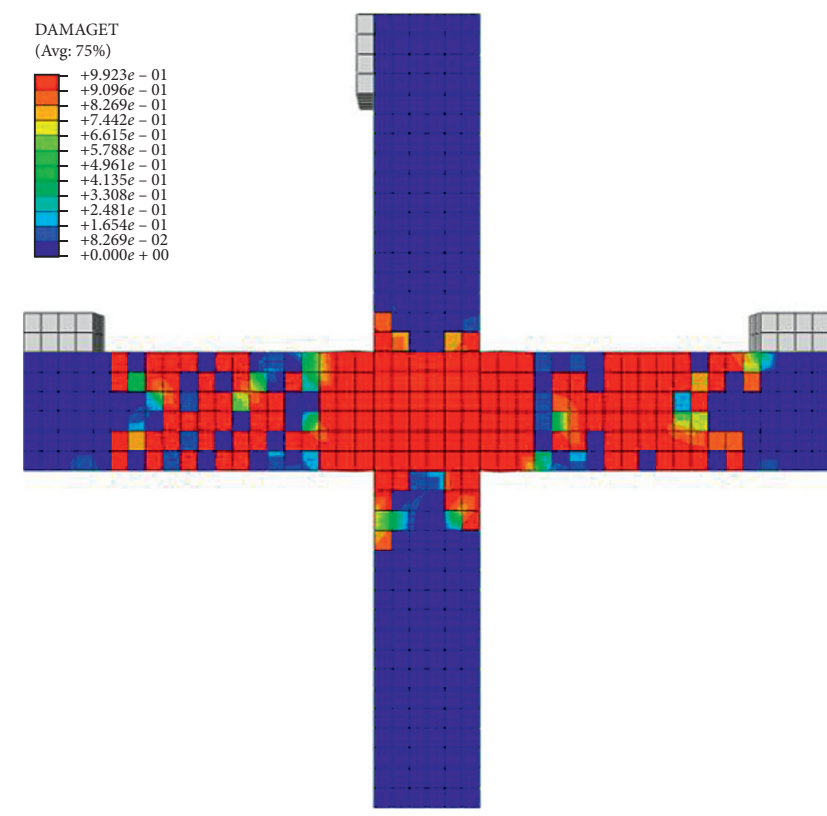

(e)

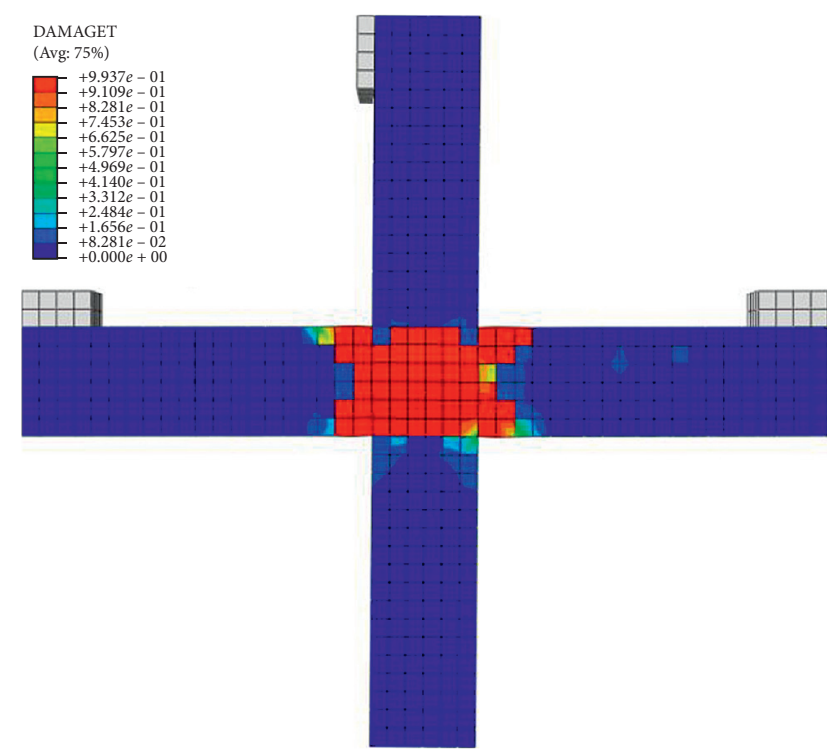

(f)

FIGURE 9: The crackle developing prefabricated reinforced concrete beam-column joints with grouted sleeves by finite element simulation. (a) Tensile damage in the beam-column interface. (b) The cracks gradually spread into beam 1. (c) The cracks gradually spread into beam 2. (d) The cracks gradually spread into beam 3. (e) Tensile cracks distribution at peak displacement loading. (f) Compressive crack distribution at peak displacement loading.

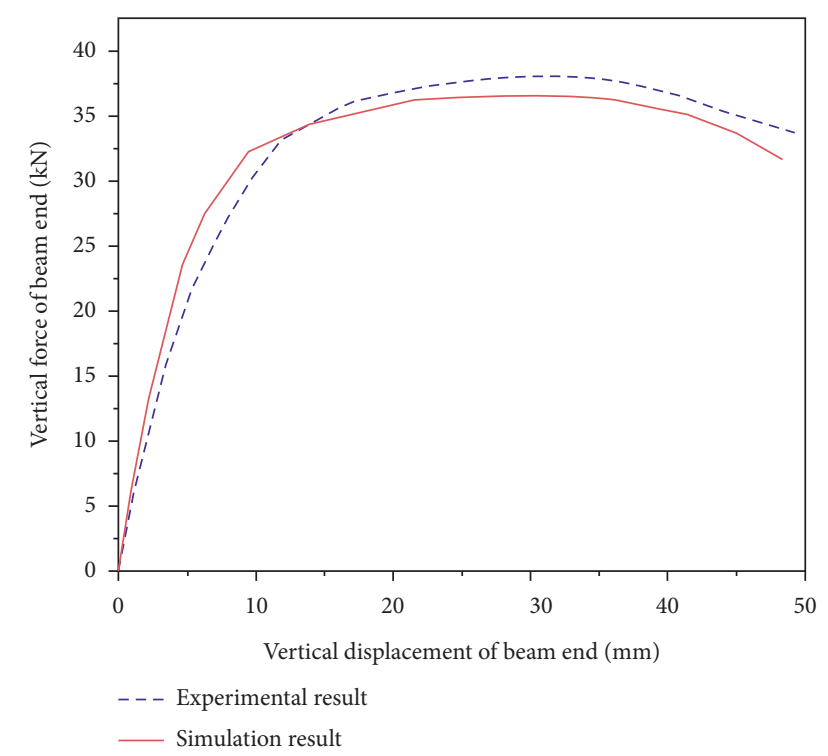

FIGURE 10: The skeleton curve of prefabricated reinforced concrete beam-column joints with grouted sleeves by finite element simulation.

hysteresis loop is similar to the test specimen and tends to be arched, it can be seen from the hysteresis loop area ratio in Table 8 that the energy dissipation capacity error of the component is relatively small when approaching the failure.

3.3.4. Strain at the Joint of the Grouted Sleeve. The strain at the grouted sleeve was measured as shown in Figure 12.
Figure 13 shows the strain value at the maximum cyclic load when the grouted sleeve joint is in a tensile state. In Figure $13, \delta$ is the loading displacement, and $\delta_{y}$ is the yield displacement. At the initial loading stage, the axial strain of the grouted sleeve and the reinforcement strain at both ends of the grouted sleeve are basically the same. Due to the large stiffness of the grouted sleeve section, the load is transferred from the beam end to the reinforcement through the grouted sleeve section, the steel bars at both ends of the grouted sleeve joints yield, with the increase in loading, the strain at both ends of the grouted sleeve (measuring points $C$ and D, as shown in Figure 12) near the core of the node increases obviously. As a result, the strain increased at the section with a large bending moment of the beam end; however, the grouted sleeve has been kept at the elastic stage, and the stress of the grouted sleeve is also similar to the experimental result.

\section{Parametric Study}

Based on the demonstrated accuracy of the developed finite element model, this section presents a parametric investigation [25] as shown in Table 9 to study the effect of different design variables (the diameter of the sleeve; the length of the sleeve; and the length of the grouted segment) on the connection performance. JD-1 model was chosen as the control specimen for the parametric analysis. Each model is briefly described in terms of variables that were adjusted, and the results are discussed. The key feature of comparison focused on the skeleton curves. Table 10 lists the eigenvalues of the skeleton curve. 
TABLE 7: The result comparison between the simulation and experiment.

\begin{tabular}{lccccccc}
\hline Parameter & $\begin{array}{c}\text { Yield } \\
\text { load } \\
(\mathrm{kN})\end{array}$ & $\begin{array}{c}\text { Yield } \\
\text { displacement } \\
(\mathrm{mm})\end{array}$ & $\begin{array}{c}\text { Peak } \\
\text { load } \\
(\mathrm{kN})\end{array}$ & $\begin{array}{c}\text { Peak } \\
\text { displacement } \\
(\mathrm{mm})\end{array}$ & $\begin{array}{c}\text { Ultimate } \\
\text { load }(\mathrm{kN})\end{array}$ & $\begin{array}{c}\text { Limit } \\
\text { displacement } \\
(\mathrm{mm})\end{array}$ & Displacement ductility coefficient \\
\hline Test result & 25.32 & 3.78 & 37.75 & 35.17 & 33.68 & 49.15 & 13.00 \\
Simulation & 27.12 & 4.04 & 36.33 & 33.28 & 32.16 & 48.38 & 11.98 \\
result & 7.11 & 6.88 & 3.76 & 5.37 & 4.72 & 1.57 & 7.84 \\
Error (\%) & & & & & & \\
\hline
\end{tabular}

*The limit displacement: since the skeleton curve does not decrease to $85 \%$ of the maximum bearing capacity, the displacement corresponding to $90 \%$ of the maximum bearing capacity is taken as the ultimate displacement in this paper.

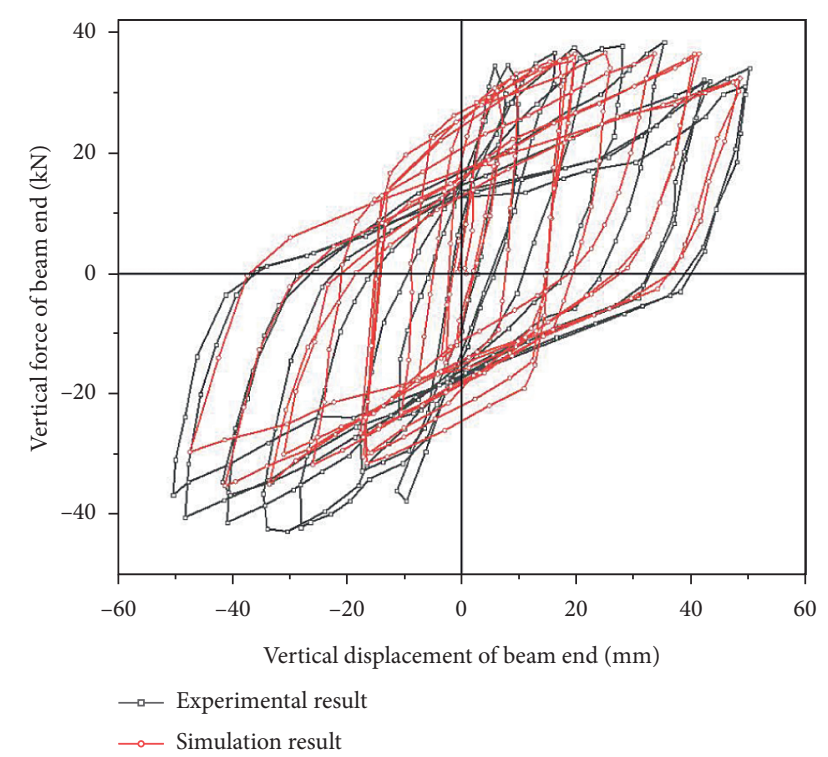

FIGURE 11: The hysteretic curve compares between the simulation and experiment.

TABLE 8: The energy dissipation capacity between the simulation and experiment.

\begin{tabular}{lccc}
\hline Area of hysteresis loop & $S_{\Delta=40 \mathrm{~mm}}$ & $S_{\Delta=45 \mathrm{~mm}}$ & $S_{\Delta=50 \mathrm{~mm}}$ \\
\hline Test result $\left(\mathrm{mm}^{2}\right)$ & 2163.31 & 2405.30 & 2560.73 \\
Simulation results $\left(\mathrm{mm}^{2}\right)$ & 1968.81 & 2111.89 & 2386.53 \\
Error (\%) & 8.99 & 12.20 & 6.80 \\
\hline
\end{tabular}

${ }^{*}$ Area of hysteresis loop: area of the hysteresis loop, respectively, represents the areas where the first displacement is loaded to the time-delay loop of $40 \mathrm{~mm}, 45 \mathrm{~mm}$, and $50 \mathrm{~mm}$, and represents the energy consumption capacity.

4.1. Effect of the Sleeve External Diameter. The external diameter of the sleeve of JD-1, JD-2, and JD-3 is $40 \mathrm{~mm}$, $44 \mathrm{~mm}$, and $48 \mathrm{~mm}$; other parameters are the same. Figure 14 shows the skeleton curves of the beam-column joints with a different external diameter of the sleeve. The comparisons of the curves show that the external diameter of the sleeve has a remarkable effect on the skeleton curves. Table 10 indicates that when the external diameter of the sleeve increases from $40 \mathrm{~mm}$ to $44 \mathrm{~mm}$, the ultimate bearing capacity is found to increase by $2.39 \%$, in contrast, the ductility factor of displacement decreases by $6.68 \%$; when the external

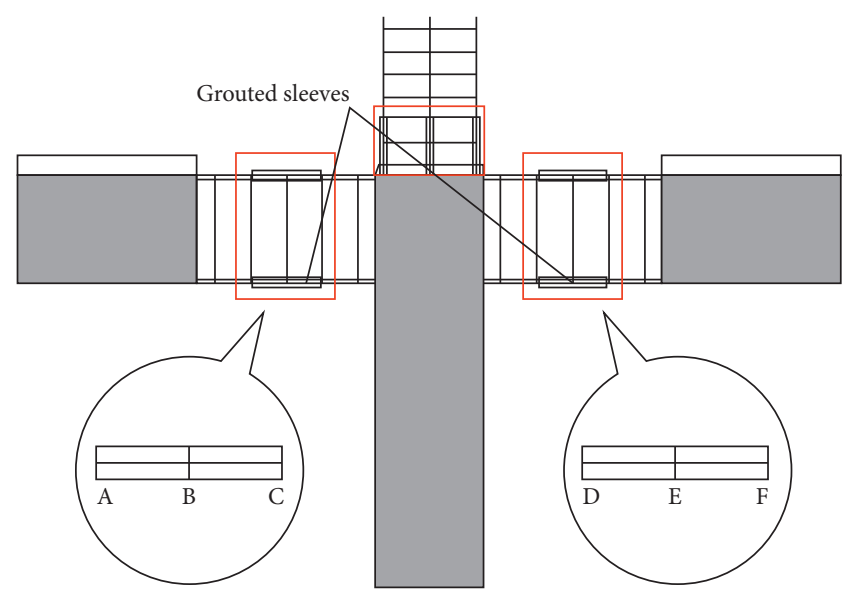

Figure 12: Position of the strain measuring point.

diameter of the sleeve increases from $44 \mathrm{~mm}$ to $48 \mathrm{~mm}$, the ultimate bearing capacity is found to decrease by $8.87 \%$, and the ductility factor of displacement decreases by $23.87 \%$. As the external diameter of the sleeve increased, the peak bearing capacity and the stiffness have obvious increase, the ductility factor of displacement is in decline. Within a certain range, the ultimate bearing capacity increases with the increase of the external diameter of the sleeve; when the diameter exceeds a certain value, the ultimate bearing capacity of the joint decreases.

4.2. Effect of the Grouted Segment Length. The lengths of the grouted segment of JD-1, JD-4, and JD-5 are $110 \mathrm{~mm}$, $100 \mathrm{~mm}$, and $130 \mathrm{~mm}$; other parameters are the same. Figure 15 shows the skeleton curves of the beam-column joints with different lengths of the grouted segment. Figure 15 indicates that the length of the grouted segment has no significant effect on the skeleton curves. The increase in the length of grouted segment leads to a slight increase in the peak bearing capacity, and the ultimate bearing capacity basically has little change. Table 10 indicates that when the length of the grouted segment increases from $100 \mathrm{~mm}$ to $110 \mathrm{~mm}$ or $130 \mathrm{~mm}$, the ultimate bearing capacity is found to increase by $0.03 \%$ and $0.81 \%$, respectively. Additionally, when the length of the grouted segment increases from $100 \mathrm{~mm}$ to $110 \mathrm{~mm}$ or $130 \mathrm{~mm}$, the ductility of the specimens did not have significant change. 


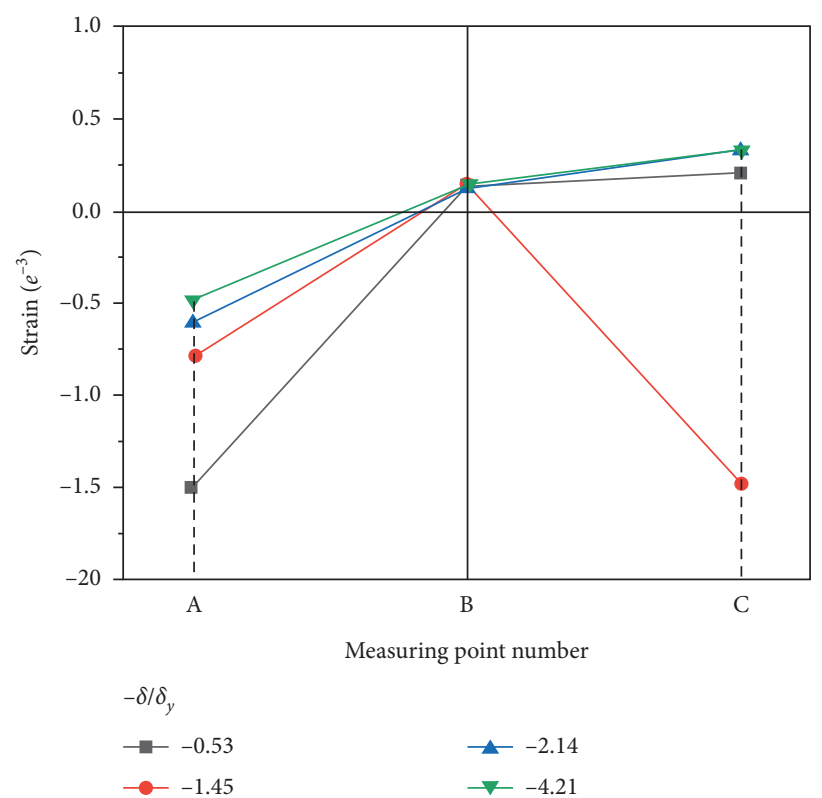

(a)

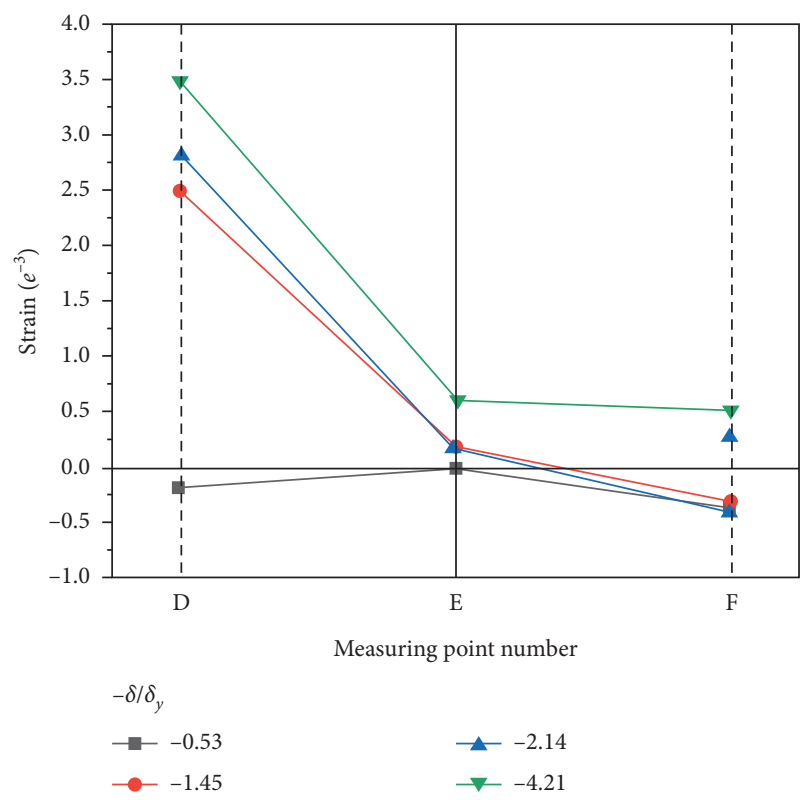

(b)

FIGURE 13: Rebar strain of grouted sleeve. (a) Strain development of sleeve joints at the bottom of beam ends in negative moment zone. (b) Strain development of sleeve joints at the bottom of beam ends in positive moment zone of beams.

TABle 9: Model parameters of parametric studies.

\begin{tabular}{lccc}
\hline Joint number & Diameter of the sleeve $(\mathrm{mm})$ & Length of sleeve $(\mathrm{mm})$ & Length of grouted segment $(\mathrm{mm})$ \\
\hline JD-1 & 40 & 159 & 110 \\
JD-2 & 44 & 159 & 110 \\
JD-3 & 48 & 159 & 110 \\
JD-4 & 40 & 159 & 100 \\
JD-5 & 40 & 159 & 130 \\
JD-6 & 40 & 150 & 110 \\
JD-7 & 40 & 143 & 110 \\
\hline
\end{tabular}

TABLE 10: The eigenvalues of the skeleton curve.

\begin{tabular}{lccccccc}
\hline $\begin{array}{l}\text { Joint } \\
\text { number }\end{array}$ & $\begin{array}{c}\text { Yield load } \\
(\mathrm{kN})\end{array}$ & $\begin{array}{c}\text { Yield displacement } \\
(\mathrm{mm})\end{array}$ & $\begin{array}{c}\text { Peak load } \\
(\mathrm{kN})\end{array}$ & $\begin{array}{c}\text { Peak displacement } \\
(\mathrm{mm})\end{array}$ & $\begin{array}{c}\text { Ultimate load } \\
(\mathrm{kN})\end{array}$ & $\begin{array}{c}\text { Limit displacement } \\
(\mathrm{mm})\end{array}$ & $\begin{array}{c}\text { Displacement ductility } \\
\text { coefficient }\end{array}$ \\
\hline JD-1 & 27.12 & 4.04 & 36.33 & 33.28 & 32.16 & 48.38 & 11.98 \\
JD-2 & 28.23 & 4.33 & 37.16 & 34.13 & 32.93 & 48.44 & 11.18 \\
JD-3 & 29.53 & 4.83 & 38.09 & 28.53 & 31.07 & 44.09 & 9.12 \\
JD-4 & 26.93 & 4.00 & 36.31 & 33.21 & 32.15 & 47.78 & 11.95 \\
JD-5 & 27.39 & 3.97 & 38.18 & 33.77 & 32.41 & 49.17 & 12.39 \\
JD-6 & 26.09 & 4.17 & 36.40 & 33.41 & 31.91 & 47.41 & 11.30 \\
JD-7 & 24.77 & 3.89 & 36.49 & 33.27 & 30.13 & 43.33 & 11.14 \\
\hline
\end{tabular}

4.3. Effect of the Sleeve Length. The lengths of the sleeve of JD-1, JD-6, and JD-7 are $159 \mathrm{~mm}, 150 \mathrm{~mm}$, and $143 \mathrm{~mm}$; other parameters are the same. Figure 16 shows the skeleton curves of the beam-column joints with different lengths of the sleeve. Figure 16 indicates that the length of the sleeve has no significant effect on the peak bearing capacity. As the sleeve length increased, the initial stiffness has an obvious decrease. Table 10 indicates that when the length of the sleeve decreases from $159 \mathrm{~mm}$ to $150 \mathrm{~mm}$ or $143 \mathrm{~mm}$, the ultimate bearing capacity is found to decrease by $0.78 \%$ and $6.31 \%$, respectively. Additionally, when the length of sleeve length decreases from $159 \mathrm{~mm}$ to $150 \mathrm{~mm}$ or $143 \mathrm{~mm}$, Table 10 shows that the length of sleeve length has little influence on the ductility. 


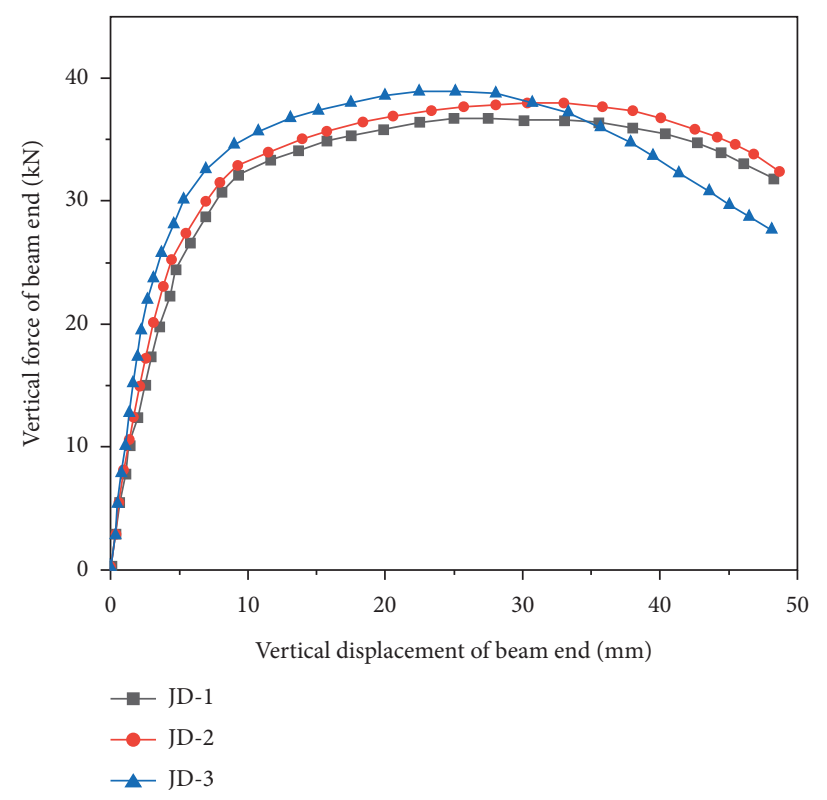

FIGURE 14: The skeleton curves of different sleeve diameters.

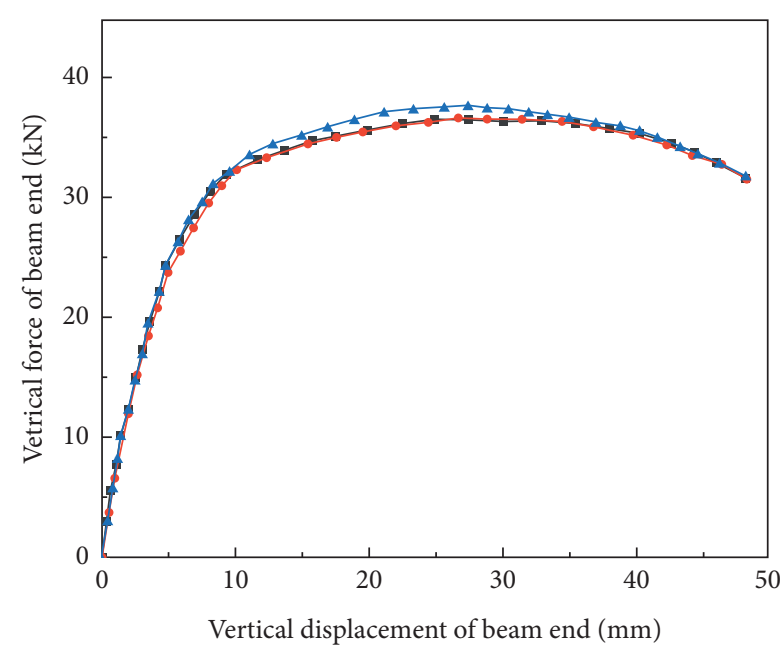

$-\mathrm{JD}-1$

$\rightarrow$ JD-4

$\longrightarrow$ JD-5

Figure 15: The skeleton curves of different grouted segment lengths.

\section{Conclusions}

In this paper, an equivalent constitutive relation is constructed for the sleeve grouted joints, and the finite element model of prefabricated beam-column joints with a grouted sleeve joint is established using a nonlinear spring element. In addition, the bond and slip between reinforced concrete and the influence of the precast and postcast concrete interface to joint performance are also considered, and the experimental results were compared with the existing research results. The main conclusions are as follows:

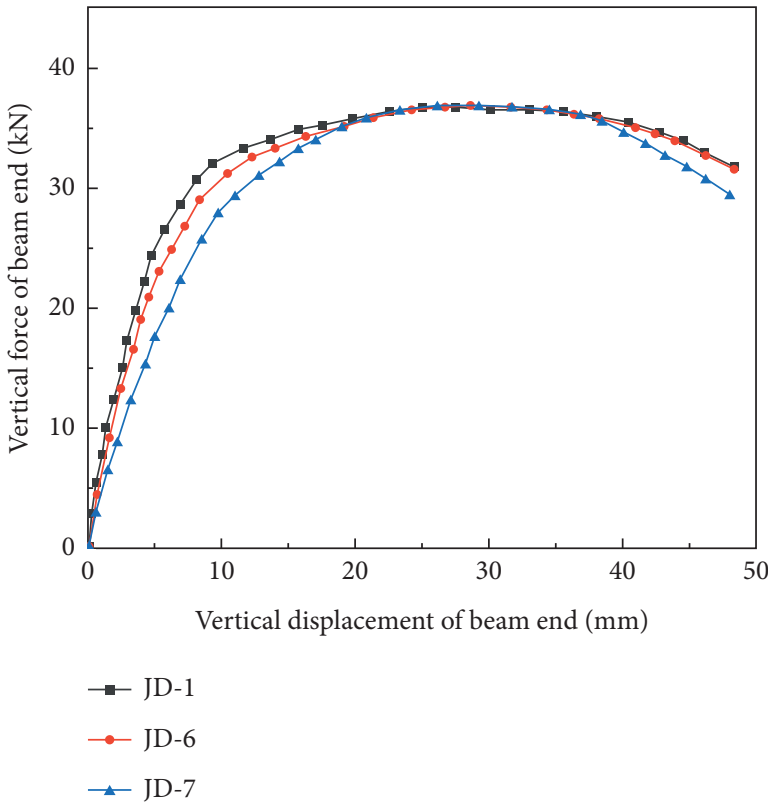

Figure 16: The skeleton curves of different sleeve lengths.

(1) The equivalent constitutive model under unidirectional tensile load is constructed based on the classification and analysis of the data obtained from the monotonic tensile test of the grouted sleeve joint specimen. The influencing factors of the constitutive model were obtained by statistical analysis software, the stress of the grouted sleeve is significantly correlated with the yield strength of the reinforcement, and the strain is significantly correlated with the yield strain of the reinforcement and the anchorage length of the reinforcement. Besides, the parameters of the relevant influencing factors are chosen. 
(2) The fracture morphology, development process, failure mode of the specimen, and stress of grouted sleeve in the loading process of the finite element model are roughly the same as the experiments, which verifies the equivalent constitutive structure of the grouted sleeve joint and the simulation method.

(3) The differences in the yield load, peak load, and ultimate load between the finite element model and test are $7.11 \%, 3.76 \%$, and $4.72 \%$, respectively. When the structure is close to failure, the skeleton curve begins to fall, which is also similar to the experiment.

(4) The hysteretic curve of the finite element model is also similar to that of the test specimens which tends to be arched. The error of the envelope area of hysteretic loop reflecting energy dissipation capacity is also below $13 \%$, in the late loading stage, due to the fact that the plastic damage of the sleeve cannot be defined.

(5) In this paper, the equivalent constitutive method based on the nonlinear spring element definition is proposed. Compared with the solid element simulation, this method not only greatly reduces the calculation time of finite element software but also effectively avoids the complicated sleeve modeling and convergence problems, which is meaningful for the grouted sleeve simulation.

(6) The finite element parameter analysis results show that the external diameter of the sleeve has a remarkable effect on the seismic performance. As the external diameter of the sleeve increases, the bearing capacity and stiffness increase significantly, and the ductility decreases. Grouted segment length has little effect on the seismic performance. Increasing the length of the sleeve length can improve the bearing capacity and rigidity of the specimen, but the ductility is reduced, and bearing capacity decreases quickly.

\section{Data Availability}

The data used to support the findings of this study are available from the corresponding author upon request.

\section{Conflicts of Interest}

The authors declare that they have no conflicts of interest.

\section{Acknowledgments}

The authors gratefully acknowledge the financial supports for this research by the Applied Basic Research Program of China's 13th Five-Year Plan (2016YFC0701705-1).

\section{References}

[1] M. J. Ameli, D. N. Brown, J. E. Parks, and C. P. Pantelides, "Seismic column-to-footing connections using grouted splice sleeves," ACI Structural Journal, vol. 113, no. 1, pp. 1021-1030, 2016.
[2] Q. Yan, T. Chen, and Z. Xie, "Seismic experimental study on a precast concrete beam-column connection with grout sleeves," Engineering Structures, vol. 155, no. 2, pp. 330-344, 2018.

[3] M. Ye, J. Jiang, H. M. Chen, H. Y. Zhou, and D. D. Song, "Seismic behavior of an innovative hybrid beam-column connection for precast concrete structures," Engineering Structures, vol. 227, no. 1, Article ID 111436, 2021.

[4] Z. Lu, J. Huang, S. Dai, J. Liu, and M. Zhang, "Experimental study on a precast beam-column joint with double grouted splice sleeves," Engineering Structures, vol. 199, no. 1, Article ID 109589, 2019.

[5] R. B. Fleischman, J. I. Restrepo, S. Pampanin, J. R. Maffei, K. Seeber, and F. A. Zahn, "Damage evaluations of precast concrete structures in the 2010-2011 canterbury earthquake sequence," Earthquake Spectra, vol. 30, no. 1, pp. 277-306, 2014.

[6] F. Xu, K. Wang, S. Wang, W. Li, W. Liu, and D. Du, "Experimental bond behavior of deformed rebars in half-grouted sleeve connections with insufficient grouting defect," Construction and Building Materials, vol. 185, no. 1, pp. 264-274, 2018.

[7] L. Di Sarno, C. Del Vecchio, G. Maddaloni, and A. Prota, "Experimental response of an existing RC bridge with smooth bars and preliminary numerical simulations," Engineering Structures, vol. 136, no. 1, pp. 355-368, 2017.

[8] C. Del Vecchio, M. Di Ludovico, A. Balsamo, and A. Prota, "Seismic retrofit of real beam-column joints using fiberreinforced cement composites," Journal of Structural Engineering, vol. 144, no. 5, Article ID 04018026, 2018.

[9] C. L. Ma, H. B. Jiang, and Z. Y. Wang, "Experimental investigation of precast RC interior beam-column-slab joints with grouted spiral-confined lap connection," Engineering Structures, vol. 196, no. 1, Article ID 109317, 2019.

[10] L. Xu, J. Pan, and J. Cai, "Seismic performance of precast RC and RC/ECC composite columns with grouted sleeve connections," Engineering Structures, vol. 188, no. 1, pp. 104-110, 2019.

[11] H. Guo, J. Zhang, and C. Wang, "Experimental study on influence of connection defects on joint strength of halfgrouted sleeve splicing of rebar," Advances in Civil Engineering, vol. 2020, Article ID 5389861, 15 pages, 2020.

[12] J. F. Rave-Arango, C. A. Blandón, J. I. Restrepo, and F. Carmona, "Seismic performance of precast concrete column-to-column lap-splice connections," Engineering Structures, vol. 172, no. 1, pp. 687-699, 2018.

[13] J. Wang, "Experimental study on seismic performance of reinforced concrete columns connected by sleeve grout anchors" Ph.D. dissertation, Xi'an University of Architecture and Technology, Xian, China, 2013.

[14] M. Â. S. Hadade, M. D. A. Ferreira, R. C. Carvalho, and B. Catoia, "Moment-rotation response of beam-column connections in precast concrete structures," Solid State Phenomena, vol. 259, no. 1, pp. 269-274, 2017.

[15] W. J. Zhao, Q. Zhong, L. L. Jia, and Y. G. Zhang, "Analysis of precast concrete frame shearwall under low cyclic loading," Journal of Shenyang Jianzhu University (Naturalence), vol. 31, no. 2, pp. 276-285, 2015.

[16] Q. W. Liu, T. Wu, H. Li, and T. J. Zhao, "Experimental research on mechanical behavior of grout sleeve splices of rebars," Industial Construction, vol. 48, no. 1, pp. 127-131, 2018.

[17] X. Zhou, Z. Zhou, and D. Gan, "Cyclic testing of square tubedreinforced-concrete column to RC beam joints," Engineering Structures, vol. 176, pp. 439-454, 2018. 
[18] S. Yu, C. Wu, F. Zhou, P. Wang, K. Zhao, and J. Liu, "Experimental study and numerical simulation of a new prefabricated SRC column to steel beam composite joint," Structures, vol. 27, no. 1, pp. 999-1010, 2020.

[19] R. Eligehausen, E. P. Popov, and V. V. Bertero, "Local bond stress-slip relationships of deformed bars under generalized excitations," in Proceedings of the 7th European Conference on Earthquake Engineering, Athens, Greece, 1982.

[20] J. Liu and G. F. Zhao, "Study of shrinkage performance of adherence of young on old concrete," Journal of Dalian University of Technology, vol. 41, no. 1, pp. 339-342, 2001.

[21] Y. Zhang, "Experimental and finite element analysis on the assembled monolithic reinforced concrete frame structure" Ph.D. dissertation, Hunan University, Changsha, China, 2015.

[22] L. Fan, Study on the shear behaviors of pre-casting and postcasting concrete interface, Ph.D. dissertation, Chongqing Jiaotong University, Chongqing, China, 2004.

[23] R. Balamuralikrishnan and J. Saravanan, "Finite element analysis of beam-column joints reinforced with GFRP reinforcements," Civil Engineering Journal, vol. 5, no. 12, pp. 2708-2726, 2019.

[24] D. Gan, Z. Zhou, X. H. Zhou, and K. H. Tan, "Seismic behavior tests of square reinforced concrete-filled steel tube columns connected to RC beam joints," Journal of Structural Engineering, vol. 145, no. 3, Article ID 04018267, 2019.

[25] Z. Zhou, D. Gan, X. H. Zhou, and K. H. Tan, "Square reinforced CFST column to RC beam joint subjected to lateral loading: An investigation using finite element analysis," in Proceedings of the 12th International Conference on Advances in Steel-Concrete Composite Structures (ASCCS 2018), València, Spain, July 2018. 